\title{
Frequency of oestrogen and progesterone receptor positivity by immunohistochemical analysis in 7016 breast carcinomas: correlation with patient age, assay sensitivity, threshold value, and mammographic screening
}

\author{
A Rhodes, B Jasani, A J Balaton, D M Barnes, K D Miller
}

\begin{abstract}
Aims-A routine immunohistochemical (IHC) assay is now commonly used for determining the oestrogen receptor (ER) and progesterone receptor (PR) status of women with breast cancer. To date, no large studies have been conducted that report the expected frequency of receptor positivity in relation to patient age and sensitivity of the IHC assay. Data on 7016 breast carcinomas from 71 laboratories were analysed to determine the frequency of receptor positivity and investigate possible causes of the observed variation in detection rates.
\end{abstract}

Methods-Members of UK NEQAS-ICC (UK National External Quality Assessment Scheme for Immunocytochemistry) provided data on the receptor status of cases routinely assayed in their departments over a period of two to 26 months between June 1996 and September 1998. Data on 7016 breast carcinomas were stratified according to patient age and receptor status. Frequency of receptor positivity was correlated with IHC assay sensitivity, the threshold value used to determine receptor positivity, and the presence or absence of mammographic screening in the hospitals or clinics served by the laboratories.

Results-The highest proportion of receptor positive cases occurred in patients in the age ranges $>65$ years for ER and $41-50$ years for PR. There was a significant positive correlation between frequency of receptor positivity and the sensitivity of the IHC assay, for both ER $\left(r_{\mathrm{s}}=0.346\right.$; $\mathrm{p}=0.019$; two tailed $)$ and PR $\left(r_{\mathrm{s}}=0.561\right.$; $\mathbf{p}=0.003$; two tailed). The mean frequency of receptor positivity for laboratories using the same $10 \%$ threshold value was $77 \%$ for ER (95\% confidence interval (CI), $74 \%$ to $80 \%$ ) in laboratories with high sensitivity and $72 \%(95 \% \mathrm{CI}, 68 \%$ to $76 \%)$ for those with low assay sensitivity $(p=0.025)$. For PR, the mean frequency of receptor positivity for laboratories using the same $10 \%$ threshold value and having high assay sensitivity was $63 \%$ (95\% CI, $57 \%$ to $69 \%$ ), and $51 \%$ (95\% CI, $38 \%$ to $65 \%$ ) for laboratories with assays of low sensitivity $(p=0.022)$. The mean frequency of ER positivity for laboratories serving hospitals and clinics where mammographic screening does and does not take place was $73.4 \%$ and $75.7 \%$, respectively ( $p=0.302$; two tailed).

Conclusions-Of the parameters investigated, patient age and IHC assay sensitivity were found to be the main variables influencing the frequency of receptor positivity. We recommend the range of receptor values obtained by laboratories achieving high assay sensitivity as a useful guide against which all laboratories can gauge their own results.

(f Clin Pathol 2000;53:688-696)

Keywords: immunohistochemistry; oestrogen receptors; progesterone receptors; frequency of positivity

The importance of determining the oestrogen receptor (ER) status of breast tumours is well established, with leading articles emphasising that the fundamental question when predicting the likely outcome that a woman might expect from tamoxifen treatment is whether or not her tumour is ER negative. ${ }^{12}$ The clinical validation of progesterone receptor (PR) status as a useful predictor of response to hormone treatment is still evolving. ${ }^{3}$ However, many laboratories now run assays for PR alongside ones for ER, because the two tests combined are thought to give enhanced predictive power. ${ }^{3}$ Receptor status is now commonly established by an immunohistochemical (IHC) assay using monoclonal antibodies. ${ }^{4-7}$ These assays have the advantage of allowing only tumour cells to be assessed for receptor status. They can also be conducted relatively inexpensively on routinely processed tissue sections with no need for specialised equipment. ${ }^{2}{ }^{8}$ Consequently, the IHC assay has become the technique of choice for establishing receptor status in diagnostic pathology departments. ${ }^{9}{ }^{10}$

With the widespread use of the IHC assay, the increasing need for effective quality assurance (QA) programmes has grown. ${ }^{9}{ }^{11}$ Since April 1994, the UK National External Quality Assessment Scheme for Immunocytochemistry (UK NEQAS-ICC) has provided such a programme for the IHC detection of ER and PR. The scheme currently evaluates laboratory performance on distributed sections from composite tissue blocks comprising tumours 
Table 1 Technical details of the immunohistochemical assays used by the laboratories participating in the survey

\begin{tabular}{|c|c|c|c|c|c|c|c|}
\hline \multicolumn{4}{|c|}{ Antibody clone } & \multicolumn{2}{|l|}{ Antigen retrieval } & \multicolumn{2}{|l|}{ Detection } \\
\hline$E R$ & $N(\%)$ & $P R$ & $N(\%)$ & System & $N(\%)$ & System & $N(\%)$ \\
\hline ID5 & $51(72 \%)$ & $1 \mathrm{~A} 6$ & $33(79 \%)$ & Microwave (MW) & $35(49 \%)$ & St ABC & $25(35 \%)$ \\
\hline $6 \mathrm{~F} 11$ & $16(23 \%)$ & KD68 & $2(5 \%)$ & Pressure cooker (PC) & $26(37 \%)$ & LSAB & $22(31 \%)$ \\
\hline \multirow[t]{4}{*}{ Unknown } & $4(6 \%)$ & Polyclonal & $1(2 \%)$ & $\mathrm{PC}$ in $\mathrm{MW}$ & $6(9 \%)$ & $\mathrm{ABC}$ & $13(18 \%)$ \\
\hline & & PgR 636 & $1(2 \%)$ & Cooker & $1(1 \%)$ & Envision $^{\mathrm{TM}}$ & $6(9 \%)$ \\
\hline & & PR 88 & $1(2 \%)$ & Autoclave & $1(1 \%)$ & Unknown & $5(7 \%)$ \\
\hline & & Unknown & $4(10 \%)$ & Unknown & $2(3 \%)$ & & \\
\hline Total & $71(100 \%)$ & & $42(100 \%)$ & & $71(100 \%)$ & & $71(100 \%)$ \\
\hline
\end{tabular}

$\mathrm{ABC}$, avidin-biotin complex; St ABC, streptomcyes ABC; LSAB, labelled St ABC; ER, oestrogen receptor; PR, progesterone receptor.

with different degrees of $\mathrm{ER}$ and $\mathrm{PR}$ expression. ${ }^{12}$

A different approach to QA was adopted by a study group of the European Organisation for Research and Treatment of Cancer (EORTC), which investigated the distribution of ER and PR in a large number of cases from seven European laboratories, as determined by enzyme immunoassay (EIA) and the radioligand binding assay (RLA). ${ }^{13}$ The authors worked on the assumption that if the natural history of breast cancer is the same in different geographical areas, then similar frequencies of receptor positivity would be expected in different laboratories. As well as determining the variation of $E R$ and $P R$ distributions between the different laboratories, the study provided useful data on the expected frequency of receptor positivity in the populations assayed.

Although various studies have shown that there is a good correlation between the results obtained by RLA, EIA, and IHC assays to predict clinical outcome of patients with breast cancer, ${ }^{14-18}$ other studies have suggested that the IHC assay is more sensitive. ${ }^{3} 19$ Consequently, the frequency of receptor positivity in breast cancers may be higher with the IHC assay than with the RLA and EIA.

The aims of our study were first to investigate the frequency of $\mathrm{ER}$ and $\mathrm{PR}$ positivity in different laboratories using the IHC assay, using a similar approach to that adopted by Romain et al in the EORTC study on cytosol based assays. ${ }^{13}$ When the frequency of positivity and variation in detection rate between laboratories had been determined, this was compared with that obtained by authors using the RLA and EIA. Lastly, we investigated possible causes of the observed variation in detection rates between different laboratories.

\section{Methods}

In July 1998, laboratories participating in UK NEQAS-ICC were posted an immunocytochemistry (ICC) research questionnaire. Participants of the scheme were invited to submit data on the last 100 cases received in their laboratory for the evaluation of hormone receptor status by IHC assay. The age of the patients was requested and whether or not the tumour was positive for ER and/or PR. No other identifying information was requested on the cases, which were coded (1-100) for each laboratory. Participants were informed that the information would be treated in the strictest of confidence and that the identity of the labora- tories voluntarily providing the data would not be released to any third party. Other information requested included: method of evaluation and threshold value used to designate cases as receptor positive or negative; the time period over which the cases were assessed; whether the hospital or clinic served by the laboratory had a breast screening programme and if so the date on which screening was introduced. Participants were asked to return the completed questionnaire by 15 September 1998. The details of the IHC assays used by the laboratories participating in the survey were obtained from the technical data provided by the same laboratories when participating in the UK NEQAS-ICC during the time period stipulated (table 1 ).

ANALYSIS OF DATA AND STATISTICAL METHODS Data provided by laboratories were entered into an SPSS 7.0 statistical program. For the purposes of establishing the total frequency of ER and PR positivity, all cases were summed together and cross tabulated with patient age, irrespective of whether laboratories provided data on more or less than 100 cases. For the purposes of investigating interlaboratory variation, only data from participants who volunteered information on at least 100 cases were included. When data on more than this were provided, either the 100 cases indicated as being most representative or the data on the last 100 cases were used.

Stratification and correlation of ER positivity with PR positivity

Frequency of ER positivity was stratified with the frequency of PR positivity for the same cases and at different age groups for laboratories providing data on both receptors. The correlation of frequency of ER positivity with frequency of PR positivity was tested using Pearson's correlation coefficient $(r)$, for laboratories providing data on both receptors and a minimum of 100 cases.

Determination of variation in receptor distribution between different laboratories

The mean frequency of receptor positivity was established to calculate the coefficient of variation.

Influence of IHC assay sensitivity on the frequency of receptor positivity

To investigate the influence of IHC assay sensitivity on the proportion of cases reported as receptor positive, the frequency of positivity 
Table 2 The frequency of oestrogen receptor (ER) positivity, with respect to patient age, of 7016 breast carcinomas as determined by the immunohistochemical assay

\begin{tabular}{lll}
\hline Age in years & $\begin{array}{l}\text { No. cases ER positive } \\
(\%)\end{array}$ & $\begin{array}{l}\text { Total no. of cases in each } \\
\text { age group }\end{array}$ \\
\hline$<21$ & $3(75.00 \%)$ & $4(0.06 \%)$ \\
$21-30$ & $31(50.82 \%)$ & $61(0.87 \%)$ \\
$31-40$ & $323(62.24 \%)$ & $519(7.40 \%)$ \\
$41-45$ & $405(69.11 \%)$ & $586(8.35 \%)$ \\
$46-50$ & $651(73.98 \%)$ & $880(12.54 \%)$ \\
$51-55$ & $696(72.88 \%)$ & $955(13.61 \%)$ \\
$56-65$ & $1185(74.06 \%)$ & $1600(22.81 \%)$ \\
$66-75$ & $1031(76.88 \%)$ & $1341(19.11 \%)$ \\
$>75$ & $826(77.20 \%)$ & $1070(15.25 \%)$ \\
Total & $5151(73.42 \%)$ & $7016(100 \%)$ \\
\hline
\end{tabular}

Table 3 The frequency of progesterone (PR) positivity, with respect to patient age, of 4056 breast carcinomas as determined by the immunohistochemical assay

\begin{tabular}{lll}
\hline Age in years & $\begin{array}{l}\text { No. cases PR positive } \\
(\%)\end{array}$ & $\begin{array}{l}\text { Total no. of cases in each } \\
\text { age group }\end{array}$ \\
\hline$<21$ & $3(100.00 \%)$ & $3(0.08 \%)$ \\
$21-30$ & $20(50.00 \%)$ & $40(0.96 \%)$ \\
$31-40$ & $150(51.37 \%)$ & $292(7.06 \%)$ \\
$41-45$ & $214(63.50 \%)$ & $337(8.34 \%)$ \\
$46-50$ & $345(63.42 \%)$ & $544(13.25 \%)$ \\
$51-55$ & $294(56.54 \%)$ & $520(12.69 \%)$ \\
$56-65$ & $534(55.74 \%)$ & $958(23.66 \%)$ \\
$66-75$ & $461(59.41 \%)$ & $776(19.32 \%)$ \\
$>75$ & $335(57.17 \%)$ & $586(14.66 \%)$ \\
Total & $2356(58.10 \%)$ & $4056(100 \%)$ \\
\hline
\end{tabular}

was compared with the numerical scores achieved by these laboratories when participating in UK NEQAS-ICC. Briefly, this scoring system consists of a sliding scale ranging from 4 to 20. Marks are awarded on this scale according to the level of IHC sensitivity achieved. A total mark $\geqslant 13 / 20$ indicates that the participant has achieved sufficient assay sensitivity to demonstrate the hormone receptor positive tumours circulated at assessment by UK NEQAS-ICC. A total mark $\leqslant 12 / 20$ is given for staining that has not achieved adequate demonstration of receptors in these tumours. Receptor expression in the tumours was established by biochemical analysis using the RLA and by the IHC assays of participating laboratories known to have validated their results clinically. The median score for each laboratory from three UK NEQAS-ICC assessments was correlated to the frequency of receptor positivity recorded by the same laboratories. The assessment runs chosen were those that corresponded to the receptor in question, and the time period during which the frequency of receptor positivity data was collected. Spearman's coefficient was used to test for the degree of correlation between frequency of receptor positivity and assay sensitivity (the median score from the three assessments). The $\chi^{2}$ test was used to compare the proportion of laboratories responding to the survey with sensitive assays with the proportion of laboratories with sensitive assays not responding to the survey.

Determination of variation in receptor distribution between laboratories with high and low assay sensitivity

The coefficient of variation, mean frequency of positivity, and mean age of patients were determined for laboratories whose median assessment score was $\geqslant 13 / 20$ and for those whose median assessment score was $\leqslant 12 / 20$. The Mann-Whitney U rank sum test and the $t$ test for two independent samples were used to test for differences in the frequency of receptor positivity between the two groups.

\section{Influence of threshold value on frequency of receptor positivity}

The frequency of receptor positivity for each laboratory was correlated with the threshold values used by the same laboratories to define receptor positive cases. The mean frequency of receptor positivity was determined for all laboratories that used the $10 \%$ threshold value. ${ }^{12}{ }^{16-18} 20-23$ These were subdivided into the two groups described above whose median scores were $\geqslant 13 / 20$ and $\leqslant 12 / 20$, respectively, when participating in the UK NEQAS-ICC assessments.

Relation between mammographic screening programmes and the frequency of ER positivity The frequency of receptor positivity was correlated with whether or not the hospital or clinic served by the laboratory participated in a mammographic screening programme.

\section{Results}

FREQUENCY OF ER AND PR POSITIVITY

ACCORDING TO AGE

Of the 235 laboratories participating in the UK NEQAS-ICC programme for hormone receptors, $71(30 \%)$ returned data on ER status for a total of 7016 cases investigated in their departments for time intervals ranging from two to 26 months between June 1996 and September 1998. Of these cases, data on PR status were provided for 4056 of the cases. Tables 2-5 present the frequency of ER and PR positivity with respect to the age of patients. The highest

Table 4 The oestrogen receptor (ER) and progesterone receptor (PR) status of the 4053 cases from the 42 laboratories that provided data on both receptors, with respect to patient age

\begin{tabular}{llllll}
\hline Age in years & ER +ve/PR +ve & ER -ve/PR -ve & ER +ve/PR-ve & ER-ve/PR +ve & $\begin{array}{l}\text { Total no. in each } \\
\text { age group }\end{array}$ \\
\hline $21-30$ & $18(45.0 \%)$ & $17(42.5 \%)$ & $3(7.5 \%)$ & $2(5.0 \%)$ & $40(1.0 \%)$ \\
$31-40$ & $134(45.9 \%)$ & $97(33.2 \%)$ & $45(15.4 \%)$ & $16(5.5 \%)$ & $292(7.2 \%)$ \\
$41-45$ & $195(57.9 \%)$ & $88(26.1 \%)$ & $35(10.4 \%)$ & $19(5.6 \%)$ & $337(8.3 \%)$ \\
$46-50$ & $319(58.6 \%)$ & $116(21.3 \%)$ & $83(15.3 \%)$ & $26(4.8 \%)$ & $544(13.4 \%)$ \\
$51-55$ & $278(53.5 \%)$ & $114(21.9 \%)$ & $112(21.5 \%)$ & $16(3.1 \%)$ & $520(12.8 \%)$ \\
$56-60$ & $239(51.0 \%)$ & $102(21.8 \%)$ & $111(23.7 \%)$ & $16(3.4 \%)$ & $468(11.6 \%)$ \\
$61-65$ & $271(55.3 \%)$ & $98(20.0 \%)$ & $113(23.1 \%)$ & $8(1.6 \%)$ & $490(12.1 \%)$ \\
$66-70$ & $251(57.2 \%)$ & $85(19.4 \%)$ & $94(21.4 \%)$ & $9(2.1 \%)$ & $439(10.8 \%)$ \\
$71-75$ & $194(57.6 \%)$ & $60(17.8 \%)$ & $76(22.6 \%)$ & $7(2.1 \%)$ & $337(8.3 \%)$ \\
$>75$ & $323(55.1 \%)$ & $119(20.3 \%)$ & $132(22.5 \%)$ & $12(2.1 \%)$ & $586(14.5 \%)$ \\
Total (receptor status) & $2222(54.8 \%)$ & $896(22.1 \%)$ & $804(19.8 \%)$ & $131(3.2 \%)$ & $4053(100 \%)$ \\
\hline
\end{tabular}


Table 5 The oestrogen receptor (ER) and progesterone receptor (PR) status of the 1985 cases from the 16 laboratories with high assay sensitivity for both ER and PR, with respect to patient age

\begin{tabular}{llllll}
\hline Age in years & & & & & $\begin{array}{l}\text { Total no. in each } \\
\text { age group }\end{array}$ \\
\hline $21-30$ & $E R+v e / P R+v e$ & $E R-v e / P R-v e$ & $E R+v e / P R-v e$ & $E R-v e / P R+v e$ & $13(1.0 \%)$ \\
$31-40$ & $5(38.5 \%)$ & $6(46.2 \%)$ & $1(7.7 \%)$ & $1(7.7 \%)$ & $147(7.4 \%)$ \\
$41-45$ & $77(42.4 \%)$ & $43(29.3 \%)$ & $20(13.6 \%)$ & $7(4.8 \%)$ & $174(8.8 \%)$ \\
$46-50$ & $106(60.9 \%)$ & $44(25.3 \%)$ & $15(8.6 \%)$ & $9(5.2 \%)$ & $268(13.5 \%)$ \\
$51-55$ & $165(61.6 \%)$ & $46(17.2 \%)$ & $44(16.4 \%)$ & $13(4.9 \%)$ & $259(13.1 \%)$ \\
$56-60$ & $153(59.1 \%)$ & $47(18.2 \%)$ & $52(20.1 \%)$ & $7(2.7 \%)$ & $433(11.7 \%)$ \\
$61-65$ & $128(54.9 \%)$ & $48(20.6 \%)$ & $51(21.9 \%)$ & $6(2.6 \%)$ & $239(12.0 \%)$ \\
$66-70$ & $149(62.3 \%)$ & $39(16.3 \%)$ & $49(20.5 \%)$ & $2(1.0 \%)$ & $204(10.3 \%)$ \\
$71-75$ & $122(59.8 \%)$ & $35(17.2 \%)$ & $43(21.1 \%)$ & $4(2.0 \%)$ & $155(7.8 \%)$ \\
$>75$ & $100(64.5 \%)$ & $20(12.9 \%)$ & $31(20.0 \%)$ & $4(2.6 \%)$ & $293(14.8 \%)$ \\
Total (receptor status) & $169(57.7 \%)$ & $51(17.4 \%)$ & $68(23.2 \%)$ & $5(1.7 \%)$ & $1985(100 \%)$ \\
\hline
\end{tabular}

proportion of receptor positive cases occurred in patients in the age ranges $>65$ years for ER and 41-50 years for PR. The proportion of cases positive for both receptors was $54.8 \%$, negative for both receptors $22.1 \%$, ER positive/PR negative $19.8 \%$, and ER negative/PR positive $3.2 \%$ (table 4 ). The highest proportion of tumours negative for both receptors occurred in patients $<46$ years, whereas the highest proportion of ER negative/PR positive tumours occurred in age groups $<51$ years. There was a significant positive correlation between the frequency of ER positivity and the frequency of PR positivity for the same cases from 26 laboratories providing data on a minimum of 100 cases and both receptors (Pearson's $r=0.526$; $\mathrm{p}=0.006$; two tailed).

DETERMINATION OF VARIATION IN FREQUENCY OF RECEPTOR POSITIVITY BETWEEN LABORATORIES Forty eight laboratories provided data on ER status on at least 100 cases and 26 of these also provided data on PR status for the same cases. The coefficient of variation $(\mathrm{CV})$ at each age group ranged from $13.3 \%$ to $23.6 \%$ for ER and $25.8 \%$ to $35.9 \%$ for PR. The CV for all ages combined was $10.3 \%$ for ER and $23.1 \%$ for PR (tables 6 and 7).
INFLUENCE OF IHC ASSAY SENSITIVITY ON THE FREQUENCY OF RECEPTOR POSITIVITY

There was a significant positive correlation between the frequency of receptor positivity and the sensitivity of the IHC assays used by the same laboratories for both ER (Spearman's correlation coefficient $\left(r_{\mathrm{s}}\right)=0.346 ; \mathrm{p}=0.019$; two tailed) and PR $\left(r_{\mathrm{s}}=0.561 ; \mathrm{p}=0.003\right.$; two tailed) (figs 1 and 2). The proportion of ER positive/PR positive, ER negative/PR negative, ER positive/PR negative, and ER negative/PR positive tumours in laboratories defined as having high IHC assay sensitivity for both receptors was; $59.1 \%, 19.1 \%, 18.8 \%$, and $2.9 \%$, respectively (table 5 ). Of these, 15 of 16 used a $10 \%$ threshold value for determining receptor status.

The proportion of laboratories with high assay sensitivity for ER (median score $\geqslant 13$ / 20 ) in the group of participants responding to the survey was 43 of $68(63 \%)$. This was significantly higher than in the group not responding to the survey, of whom only 75 of $158(48 \%)$ achieved this degree of assay sensitivity $\left(\chi^{2}=16.351 ; \mathrm{p}<0.001\right)$. The proportion of laboratories with high assay sensitivity for PR (median score $\geqslant 13 / 20$ ) in the group of participants responding to the survey was 29 of $40(73 \%)$. Similarly, this was significantly higher than in the group not responding

Table 6 Coefficients of variation (CV) for the 48 laboratories that returned data for oestrogen receptors (ER) on a minimum of 100 cases

\begin{tabular}{|c|c|c|c|c|c|c|c|c|}
\hline & \multirow[b]{2}{*}{$N$} & \multicolumn{7}{|c|}{$C V$ for ER according to patient age range (years) } \\
\hline & & $31-45$ & $46-50$ & $51-55$ & $56-65$ & $66-75$ & $>75$ & All ages \\
\hline All laboratories & 48 & $23.6 \%$ & $19.8 \%$ & $20.5 \%$ & $13.3 \%$ & $16.7 \%$ & $17.7 \%$ & $10.3 \%$ \\
\hline Laboratories with high assay sensitivity & 30 & $18.1 \%$ & $18.0 \%$ & $18.9 \%$ & $13.7 \%$ & $15.7 \%$ & $13.9 \%$ & $7.6 \%$ \\
\hline Laboratories with low assay sensitivity & 16 & $31.2 \%$ & $23.3 \%$ & $23.2 \%$ & $12.6 \%$ & $18.4 \%$ & $18.8 \%$ & $13.5 \%$ \\
\hline
\end{tabular}

Two laboratories participating in this survey that provided data on ER did not participate in the UK NEQAS-ICC for hormonal receptors during the period in which data were collected. The data from these two laboratories were therefore not included in any of the analyses involving immunohistochemical assay sensitivity.

Table 7 Coefficients of variation (CV) for the 26 laboratories who returned data for progesterone receptors (PR) on a minimum of 100 cases

\begin{tabular}{|c|c|c|c|c|c|c|c|c|}
\hline & \multirow[b]{2}{*}{$N$} & \multicolumn{7}{|c|}{$C V$ for $P R$ according to patient age range (years) } \\
\hline & & $31-45$ & $46-50$ & $51-55$ & $56-65$ & $66-75$ & $>75$ & All ages \\
\hline All laboratories & 26 & $28.7 \%$ & $25.8 \%$ & $29.2 \%$ & $28.6 \%$ & $31.4 \%$ & $35.9 \%$ & $23.1 \%$ \\
\hline Laboratories with high assay sensitivity & 18 & $27.5 \%$ & $23.0 \%$ & $22.8 \%$ & $25.0 \%$ & $32.3 \%$ & $31.8 \%$ & $20.1 \%$ \\
\hline Laboratories with low assay sensitivity & 7 & $28.2 \%$ & $32.7 \%$ & $37.5 \%$ & $38.5 \%$ & $28.0 \%$ & $46.4 \%$ & $28.4 \%$ \\
\hline
\end{tabular}

One laboratory participating in this survey that provided data on PR did not participate in the UK NEQAS-ICC for hormonal receptors during the period in which receptor data were collected. The data from this laboratory were therefore not included in any of the analyses involving immunohistochemical assay sensitivity. 


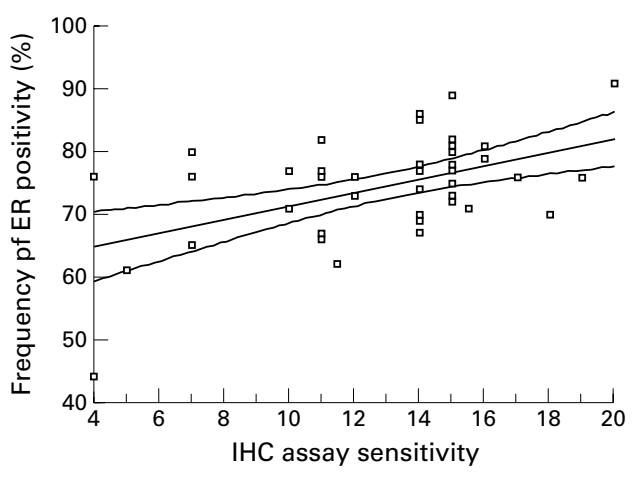

Figure 1 Scatter diagram to show the relation between the frequency of oestrogen receptor (ER) positivity in 46 laboratories and the immunohistochemical (ICH) assay sensitivity (median score achieved for assessment runs 40, 41, and 42). A least squares linear regression line is shown with 95\% confidence interval, giving the best fit for all the data points. Spearman's correlation coefficient $=0.346$ $p=0.019$ (two tailed)

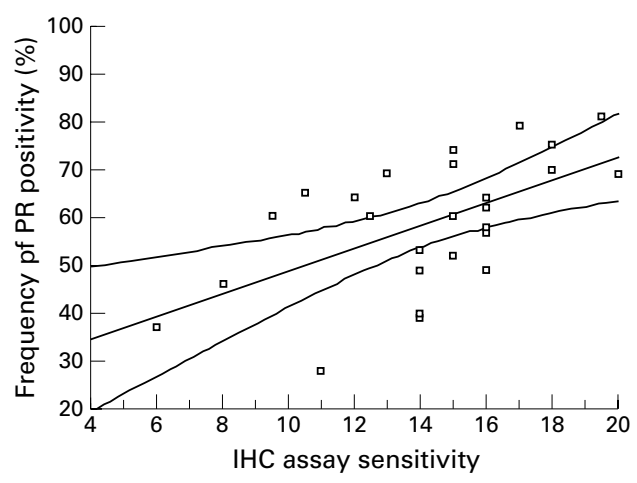

Figure 2 Scatter diagram to show the relation between the frequency of progesterone receptor (PR) positivity in 46 laboratories and the immunohistochemical (ICH) assay sensitivity (median score achieved for assessment runs 36, 39, and 41). A least squares linear regression line is shown with 95\% confidence interval, giving the best fit for all the data points. Spearman's correlation coefficient $=0.561$, $p=0.003$ (two tailed)

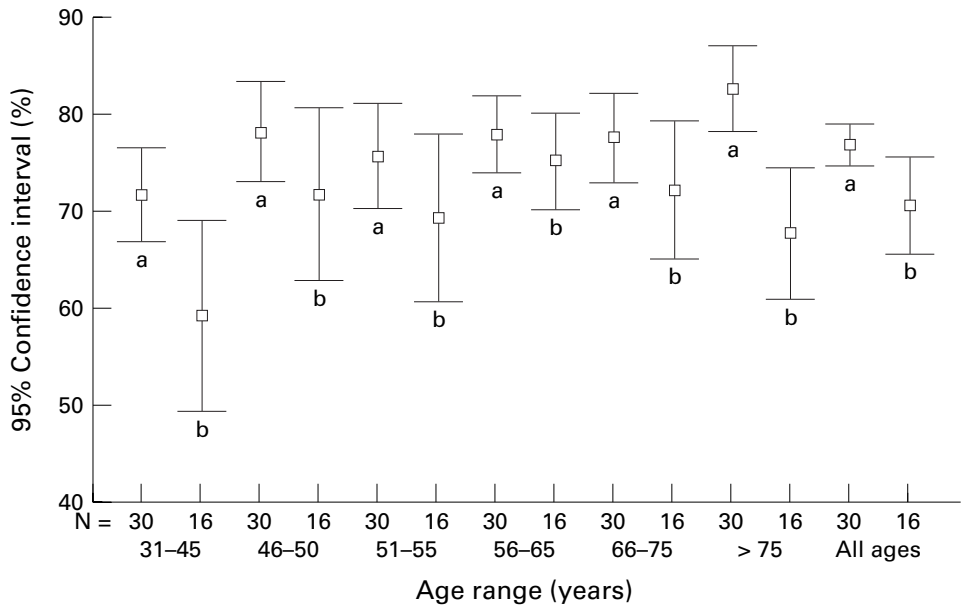

Figure 3 The mean frequency of oestrogen receptor (ER) positivity at different patient age ranges for laboratories with high assay sensitivity $(n=30$, labelled " $a$ ") and low assay sensitivity ( $n=16$, labelled " $b$ "). High assay sensitivity is defined as a median score $\geqslant 13 / 20$ in assessment runs 40,41, and 42; low assay sensitivity is defined as a median score $\leqslant 12 / 20$ in assessment runs 40,41 , and 42. to the survey, of whom 84 of 137 (61\%) achieved this level of assay sensitivity $\left(\chi^{2}=9.492 ; \mathrm{p}<0.02\right)$.

INVESTIGATION OF VARIATION IN FREQUENCY OF RECEPTOR POSITIVITY BETWEEN LABORATORIES WITH HIGH AND LOW ASSAY SENSITIVITY

Figures 3 and 4 show the mean frequency of receptor positivity at each age group in laboratories with high assay sensitivity (median score $\geqslant 13 / 20$ ) and those with low assay sensitivity (median score $\leqslant 12 / 20$ ). The Mann-Whitney $U$ test showed a significant difference in the distribution of receptor positivity between laboratories with high assay sensitivity and those with low assay sensitivity for ER for the age groups 31-45, 51-55, and $>75$ years, and when all ages are combined (table 8). For PR, the significant differences were found in the 31-45 and 51-55 year age ranges and when all ages are combined (table 9). In five of six of the age groups, the CV was smaller for laboratories with high assay sensitivity than for laboratories with low assay sensitivity for both ER and PR. Overall, the $\mathrm{CV}$ for laboratories with high assay sensitivity was $7.6 \%$ for ER and $20.1 \%$ for PR, whereas for laboratories with low assay sensitivity the CVs for ER and PR were $13.5 \%$ and $28.4 \%$, respectively (tables 6 and 7). The mean age of patients from laboratories with high and low sensitivity assays for ER was 59.7 and 61.6 years, respectively. The mean age of patients from laboratories with high and low sensitivity assays for PR was 59.3 and 62.2 years, respectively.

INFLUENCE OF THRESHOLD VALUE ON FREQUENCY OF RECEPTOR POSITIVITY Of the laboratories providing data on at least 100 cases, 43 of 48 gave details of the method of evaluation used to determine receptor positivity. The method of evaluation used by 34 of $48(70.8 \%)$ laboratories for ER and 25 of 26 (96.2\%) laboratories for PR was the $10 \%$ threshold. ${ }^{12}{ }^{16-18} 20-23$ With this method, $\geqslant 10 \%$ of invasive tumour nuclei staining is deemed to be a positive result, irrespective of staining intensity. Other threshold values and scoring systems used to determine ER status included a $20 \%$ threshold $(n=3)$, a $5 \%$ threshold $(n=2)$, the category score $(\mathrm{n}=2)$, "H" score $(\mathrm{n}=2)$, and value not disclosed $(n=5)$.

The $95 \%$ confidence interval (CI) for the frequency of ER positivity for laboratories using the $10 \%$ threshold was $73 \%$ to $78 \%$, with a mean value of $75 \%$, whereas that for frequency of PR positivity was $54 \%$ to $65 \%$, with a mean value of $59 \%$. The mean values for laboratories using this threshold with high and low assay sensitivity for ER were $77 \%$ (95\% CI, $74 \%$ to $80 \%$ ) and $72 \%$ (95\% CI, $68 \%$ to $76 \%)$, respectively $(t=2.000$; $\mathrm{p}=0.025)$, whereas those for PR were $63 \%$ (95\% CI, $57 \%$ to $69 \%$ ) and $51 \%$ (95\% CI, $38 \%$ to $65 \%)$, respectively $(t=2.127$; $\mathrm{p}=0.022)$. The $t$ test values $(t)$, confirmed that the frequencies of receptor positivity recorded in laboratories with high assay 


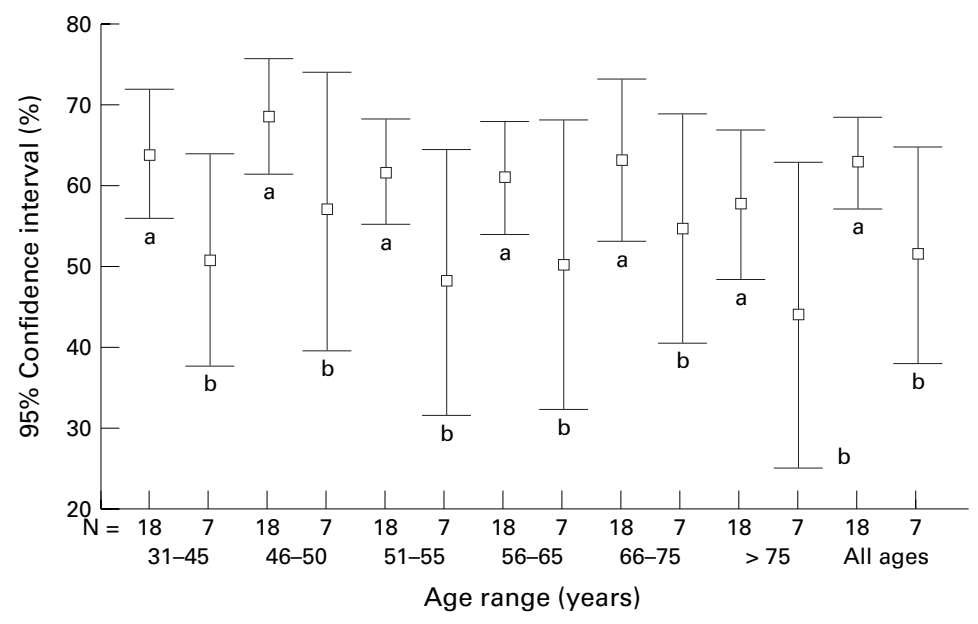

Figure 4 The mean frequency of progesterone receptor (PR) positivity at different patient age ranges for laboratories with high assay sensitivity $(n=18$, labelled " $a$ ") and low assay sensitivity ( $n=7$, labelled " $b$ "). High assay sensitivity is defined as a median score $\geqslant 13 / 20$ in assessment runs 36, 39, and 41; low assay sensitivity is defined as a median score $\leqslant 12 / 20$ in assessment runs 36,39 , and 41 .

Table 8 Differences in the distribution of oestrogen receptor (ER) positivity between laboratories with high assay sensitivity and those with low assay sensitivity

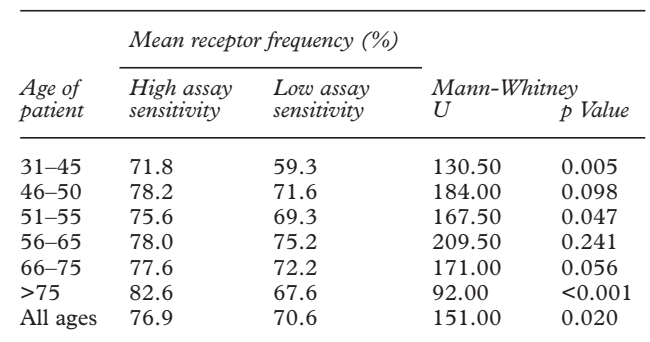

High assay sensitivity defined as a median score $\geqslant 13 / 20$ in UK NEQAS assessment runs 40,41 , and 42 ; low assay sensitivity defined as a median score $\leqslant 12 / 20$ in UK NEQAS assessment runs 40,41 , and 42 .

Table 9 Differences in the distribution of progesterone receptor (PR) positivity between laboratories with high assay sensitivity and those with low assay sensitivity

\begin{tabular}{|c|c|c|c|c|}
\hline \multirow[b]{2}{*}{$\begin{array}{l}\text { Age of } \\
\text { patient }\end{array}$} & \multicolumn{2}{|c|}{ Mean receptor frequency (\%) } & \multirow[b]{2}{*}{$\begin{array}{l}\text { Mann-Whitn } \\
U\end{array}$} & \multirow[b]{2}{*}{ ney } \\
\hline & $\begin{array}{l}\text { High assay } \\
\text { sensitivity }\end{array}$ & $\begin{array}{l}\text { Low assay } \\
\text { sensitivity }\end{array}$ & & \\
\hline $31-45$ & 63.9 & 50.7 & 33.00 & 0.035 \\
\hline $46-50$ & 69.0 & 56.9 & 40.00 & 0.082 \\
\hline $51-55$ & 61.7 & 48.0 & 35.00 & 0.045 \\
\hline $56-65$ & 60.9 & 50.2 & 44.50 & 0.132 \\
\hline $66-75$ & 63.2 & 54.7 & 47.50 & 0.174 \\
\hline$>75$ & 57.7 & 44.0 & 37.50 & 0.062 \\
\hline All ages & 62.8 & 51.4 & 35.50 & 0.048 \\
\hline
\end{tabular}

High assay sensitivity defined as a median score $\geqslant 13 / 20$ in UK NEQAS assessment runs 36,39 , and 41 ; low assay sensitivity defined as a median score $\leqslant 12 / 20$ in UK NEQAS assessment runs 36,39 , and 41 .

sensitivity were significantly higher than those recorded in laboratories with low assay sensitivity. These differences were independent of the threshold value used by these laboratories.

INFLUENCE OF MAMMOGRAPHIC SCREENING PROGRAMMES ON THE FREQUENCY OF ER POSITIVITY

The mean frequencies of ER positivity for laboratories serving hospitals or clinics where mammographic screening did and did not take place were $73.4 \%$ (95\% CI, $70 \%$ to $77 \%$ ) and
$75.7 \%$ (95\% C1, $72 \%$ to $79 \%$ ), respectively. The Mann-Whitney U test confirmed that there was no significant difference between these two distributions $\quad(\mathrm{U}=224.500$; $\mathrm{p}=0.302$ ).

\section{Discussion}

The use of questionnaires or surveys to provide solutions to QA issues is not a new idea and is an established part of the College of American Pathologists Q-probes programme. ${ }^{24}$ Our study combined this approach to QA with that of Romain and colleagues ${ }^{13}$ to investigate the frequency of receptor positivity as determined by the IHC assay in laboratories participating in a national external quality assessment (EQA) scheme.

The cumulative data on the 7016 cases subjected to IHC analysis gave an overall frequency for ER positivity of $73.42 \%$ (table 2). This correlates well with the results obtained by de Mascarel et al using dextran charcoal and IHC assays on 938 metastatic free invasive ductal carcinomas of which $73 \%$ and $75 \%$, respectively, were ER positive. ${ }^{16}$

Data were provided in our study for both ER and PR on 4056 cases. The cumulative data for PR gave an overall frequency of positivity of $58.10 \%$ (table 3 ), slightly higher than the $56 \%$ obtained by MacGrogan et al using the dextran charcoal assay on the same cases as were used in the de Mascarel study. ${ }^{16}{ }^{17}$ However, it is very similar to the value of $58.4 \%$ PR positivity obtained by MacGrogan et al, when using the IHC assay. ${ }^{17}$

Cross tabulation of ER and PR status on the 4056 cases in our study revealed $54.8 \%$ positive for both receptors, $22.1 \%$ negative for both receptors, $19.8 \%$ ER positive/PR negative, and 3.2\% ER negative/PR positive (table 4). These results are similar to those obtained by Reiner et al using the Abbott ER and PR monoclonal kits (Abbott Laboratories, North Chicago, Illinois, USA) on frozen sections from 426 cases of primary breast cancer, of which $55 \%$ were positive for both receptors, $26 \%$ negative for both receptors, $16 \%$ ER positive/PR negative, and 3\% ER negative/PR positive. ${ }^{24 a}$ The only noticeable difference was the slightly higher proportion of ER positive tumours in our study, whereas the proportion of PR positive tumours was almost identical. Similarly, comparisons with the results obtained by MacGrogan et al and de Mascarel et al using the dextran charcoal method revealed a good correlation. In these studies, $52 \%$ of cases were positive for both ER and PR, 23\% negative for both ER and PR, 21\% ER positive/PR negative, and 4\% ER negative/PR positive. ${ }^{1617}$ These figures, the ones obtained by Reiner $e t a l,{ }^{26 a}$ and those from our study are slightly different to those of McGuire et $a l,^{25}$ who used the RLA on tumours from patients with advanced metastatic breast cancer receiving endocrine treatment. MacGuire's group found that $58 \%$ of tumours were positive for both ER and PR, 15\% negative for both ER and PR, 23\% ER positive/PR negative, and $4 \%$ ER negative/PR. The differences probably result from the fact that our 
study, the ones performed by de Mascarel et al and MacGrogan et al, and most of the others performed to date have involved patient populations of mixed clinical stage and/or treatment status.

With data on over 4000 cases, it was also possible to stratify ER/PR positivity into different age groups (table 4). We were unable to find similar breakdowns in the form of either biochemical or IHC results. However, our results of the single ER and PR analyses at each age group fall within the range of the biochemical results reported by the expert laboratories in the study of Romain et al. ${ }^{13} \mathrm{We}$ are therefore confident that the combined $\mathrm{ER} / \mathrm{PR}$ results give a reasonably accurate reflection of the combined receptor status occurring at each age group.

The coefficients of variation between laboratories providing receptor data on at least 100 cases in our study were greater at each age group (13.3-23.6\% for ER, 25.8-35.9 for PR) than those obtained by Romain et al. Their results ranged from $7-19 \%$ for $\mathrm{ER}$ and $19-28 \%$ for PR. ${ }^{13}$ However, in our study, the number of cases occurring at each age group for each laboratory is small and a more accurate indication of the variation can be obtained by comparing the total receptor positivity achieved by each laboratory. These give lower CVs of $10.3 \%$ and $23.1 \%$ for ER and PR, respectively (tables 6 and 7), and both fall within the range of $\mathrm{CV}$ values recorded by Romain et al.

Several institutions participating in the UK NEQAS-ICC programme for hormonal receptors have produced results that have been clinically validated. These laboratories have confirmed a positive relation between positive receptor status determined by IHC and a favourable response to endocrine treatment, with the IHC assay being as efficient or more efficient than biochemistry. We have established previously that these laboratories consistently achieved the expected result when participating in the UK NEQAS-ICC programme for hormonal receptors. That is, at each assessment over a four year period, these laboratories consistently stained the expected proportion of ER and PR positive nuclei in low, medium, and high receptor positive tumours and were awarded numerical scores of $\geqslant 13 / 20 .{ }^{26}$ We have used these assessment scores as a gauge of IHC assay sensitivity for the laboratories participating in our present study and have correlated the numerical scores, ranging from 4 to 20, with the frequency of ER and PR positivity recorded by the same laboratories (figs 1 and 2). The significant positive correlation between assay sensitivity and frequency of receptor positivity indicates that, generally speaking, laboratories who perform well at assessment and have high assay sensitivity record a higher proportion of cases as receptor positive than those who have low assay sensitivity (figs 1 and 2). To substantiate this link, we compared the frequencies of laboratories that achieve high assay sensitivity (scores $\geqslant 13 / 20$ ), with those obtained by laboratories that achieve only low sensitivity (scores $\leqslant 12$ / 20).

The mean frequency of receptor positivity was always found to be higher in laboratories with high assay sensitivity than in laboratories with low assay sensitivity, irrespective of patient age (figs 3 and 4). In particular, the MannWhitney $U$ test showed a significant difference in the distributions of ER positivity for the two groups of laboratories for age ranges 31-45, $>75$ years, and when all ages are combined (table 8). To ensure that the age distributions were not overtly different in the two groups of laboratories, the mean age of patients of laboratories in each group was determined. Both were similar, with a mean age of 59.8 years for the group with high ER assay sensitivity and 61.6 years for the group with low assay sensitivity, whereas those for PR were 59.3 years and 62.2 years, respectively.

The choice of threshold value used by different laboratories to record whether a breast tumour is receptor positive or receptor negative could influence the frequency of positivity. Over $70 \%$ of the laboratories participating in our study used the simple but clinically validated $10 \%$ receptor positive threshold to establish ER status. ${ }^{16-18}{ }^{20-23}$ Using this threshold value the mean frequency of ER positivity reported was $75 \%$ (95\% CI, $73 \%$ to $78 \%)$. This is very close to the value of $73.4 \%$ for the frequency of ER positivity obtained in our present study for the total 7016 cases. It is also identical to the value recorded by Mascarel et al using the IHC assay and a $10 \%$ threshold. ${ }^{16}$

If the laboratories that use the $10 \%$ threshold are divided into those with high and low assay sensitivity, the same significant difference in frequency of ER positivity between the two groups of laboratories is seen, indicating that this difference is independent of the threshold value used. Arguably, therefore, a more accurate estimate of the expected frequency of ER positivity for laboratories using a $10 \%$ threshold lies within the frequency range recorded by laboratories with high assay sensitivity; that is, $74 \%$ to $80 \%(95 \% \mathrm{CI})$ or a mean frequency of $77 \%$. This result is at least $7 \%$ higher than the $60-70 \%$ of positive cases reported for the biochemical ligand binding assays over the past 20 years. ${ }^{3}$

Over $96 \%$ of the laboratories that provided data on PR on a minimum of 100 cases used a $10 \%$ threshold, with a mean frequency of positivity for these laboratories of $59 \%$. This is almost the same as the value of $58.4 \%$ obtained by MacGrogan et al using an IHC assay and a $10 \%$ threshold. ${ }^{17}$ In a similar manner to ER, an accurate estimate of the expected frequency of PR positivity for laboratories using a 10\% threshold lies within the frequency range recorded by laboratories with high assay sensitivity; that is, $57 \%$ to $69 \%(95 \% \mathrm{CI})$ or a mean frequency of $63 \%$. Again, these results are some $7 \%$ higher than those obtained by biochemistry. ${ }^{17}$

It has been suggested that the introduction of mammographic screening might influence receptor distributions. ${ }^{13}$ In our study, the mean 
frequency of ER positive tumours was slightly lower for laboratories that served hospitals where screening took place. However, there was no significant difference in the frequency of ER positivity recorded in these laboratories and that of institutions where screening did not take place.

An important consideration was whether the frequencies of receptor positivity recorded in the $30 \%$ of UK NEQAS-ICC participants responding to this survey was representative of the $70 \%$ of laboratories that did not respond. Our study showed a significant positive correlation between assay sensitivity as defined by performance in UK NEQAS-ICC assessments and the frequency of receptor positive breast carcinomas reported in the same laboratories. Therefore, if the UK NEQASICC scores for ER and PR recorded in the $70 \%$ of laboratories not responding to the survey were similar to those of the $30 \%$ that did respond, it could be assumed that the frequencies of receptor positive tumours in these laboratories would also show a similar distribution. It was found that whereas $63 \%$ and $73 \%$ of laboratories that responded to this survey had assays of high sensitivity for ER and PR, respectively, the proportions of laboratories with assays of this sensitivity in the group that did not respond were significantly lower$48 \%$ and $61 \%$, respectively. Consequently, it cannot be assumed that the overall frequencies of receptor positivity reported here are representative of the total cohort of UK NEQASICC participants. Instead, it is likely that a substantial proportion of these participants will find that their receptor values fall within the range of values equating to low assay sensitivity.

The sensitivity of any IHC assay is determined by several parameters; these include the quality and concentration of the primary antibody, the power of the antigen retrieval and secondary detection systems, and the quality of tissue fixation. ${ }^{27-29}$ Evidence to date suggests that inefficiencies in the antigen retrieval step are the most probable cause of low IHC assay sensitivity for ER. ${ }^{30}$ Therefore, laboratories with low sensitivity need to optimise this step.

We recommend that the frequencies of receptor positivity recorded for the large number of cases in our study should be used as a useful QA tool, against which laboratories can compare their current IHC assay receptor results. In particular, we recommend the range of values recorded by laboratories with high IHC assay sensitivity, because this degree of sensitivity is equivalent to that achieved by laboratories known to have clinically validated their results. Laboratories whose frequencies of receptor positive cases fall outside this range, which are shown to have low IHC assay sensitivity by their participation in a QA programme, should consider adjusting their technique accordingly.

We thank all the participants of UK NEQAS-ICC who contributed data to the survey and without whose support our study would not have been possible.
1 Early Breast Cancer Trialists' Collaborative Group. Tamoxifen for early breast cancer: an overview of the randomised trials. Lancet 1998;351:1451-67.

2 Elledge RM, Osborne CK. Oestrogen receptors and breast cancer: it is time for individualised treatment based on oestrogen receptor status. BMF 1997;314:1843-4.

3 Allred DC, Harvey JM, Berado M, et al. Prognostic and predictive factors in breast cancer by immunohistochemical analysis. Mod Pathol 1998;11:155-68.

4 Saati TAL, Clamens S, Cohen-Knafo E, et al. Production of monoclonal antibodies to human oestrogen receptor (ER) protein using recombinant ER (RER). Int 7 Cancer protein using

5 Hendricks JB, Wilkinson EJ. Comparison of two antibodies for evaluation of estrogen receptors in paraffin-embedded tumours. Mod Pathol 1993;6:765-70.

6 Sannino P, Shousha S. Demonstration of oestrogen receptors in paraffin sections of breast carcinoma using microwave oven processing. I Pathol 1993;170(suppl): 201.

7 Kell DL, Kamel OW, Rouse RV. Immunohistochemical analysis of breast carcinoma estrogen and progesterone receptors in paraffin-embedded tissue, correlation of clones ER1D5 and 1A6 with a cytosol-based hormone receptor assay. Appl Immunohistochem 1993;1:275-81.

8 Leong ASY, Milios J. Comparison of antibodies to oestrogen and progesterone receptors and the influence of microwave antigen retrieval. Appl Immunohistochem 1993;1:282-8.

9 Barnes DM, Millis RR, Beex LVA, et al. Increased use of immunohistochemistry for oestrogen receptor measurement in mammary carcinoma: the need for quality assurance. Eur F Cancer 1998;34:1677-82.

10 Elias JM. A phoenix arisen-estrogen receptor immunohistochemistry. Fournal of Histotechnology 1997;20:7-10.

11 Groupe d'Etude des Recepteurs Hormonaux par Immunohistochemie. FNCLCC/AFAQAP. Recommandations pour l'évaluation immunohistochimique des récepteurs hormonaux sur coupes en paraffine dans les carcinomes mammaires. Ann Pathol 1996;16:144-8.

12 Rhodes A, Jasani B, Barnes D, et al. The reliability of immunohistochemical demonstration of oestrogen recepors in routine practice: inter-laboratory variance in the sensitivity of detection and evaluation of scoring systems. $\mathcal{F}$ Clin Pathol 2000;53:125-30.

13 Romain S, Laine Bidron C, Martin PM, et al on behalf of the EORTC Receptor Study Group. EORTC receptor study group report. Steroid receptor distribution in 47892 breast cancers. A collaborative study of 7 European laboratories. Eur f Cancer 1995;31A:411-17.

14 Allred DC, Bustamante MA, Daniel CO, et al. Immunocytochemical analysis of estrogen receptors in human breast carcinomas. Evaluation of 130 cases and review of the literature regarding concordance with biochemical assay and clinical relevance. Arch Surg 1990;125: 107-13.

15 Barnes DM, Harris WH, Smith P, et al. Immunohistochemical determination of oestrogen receptors: comparison of different methods of assessment of staining and correlation with clinical outcome of breast cancer patients. $\mathrm{Br}$ f Cancer 1996;74:1445-51.

16 de Mascarel I, Soubeyran G, MacGrogan, J, et al. Immunohistochemical analysis of estrogen receptors in 938 breast carcinomas: concordance with biochemical assay and prognostic significance. Appl Immunohistochem 1995;3:222-31.

17 MacGrogan G, Soubeyran G, de Mascarel I, et al. Immunohistochemical detection of progesterone receptors in breast invasive ductal carcinomas: a correlative study of 942 cases. Appl Immunohistochem 1996;4:219-27.

18 Saccani JG, Johnston SRD, Salter J, et al. Comparison of new immunohistochemical assay for oestrogen receptor in human breast carcinoma in formalin-fixed paraffin embedded tissue with quantitative enzyme immunoassay. 7 Clin Pathol 1994;47:900-5.

19 Harvey JM, Clark GM, Osborne CK, et al. Estrogen receptors status by immunohistochemistry is superior to the igand-binding assay for predicting response to adjuvant endocrine therapy in breast cancer. $\mathcal{F}$ Clin Oncol 1999;17: 1474-81.

20 Pellicer EM, Sundblad A. Evaluation of antibodies to oestrogen receptors. Appl Immunohistochem 1994;2:141.

21 Pertschuk LP, Feldman JG, Kim Y-D, et al. Estrogen receptor immunocytochemistry in paraffin embedded tissues with ER1D5 predicts breast cancer endocrine response more accurately than $\mathrm{H} 222 \mathrm{Spg}$ in frozen sections or more accurately than H222Spg in frozen sections or
cytosol-based ligand-binding assays. Cancer 1996;77:251419.

22 Ferno M, Andersson C, Giita F, et al. Oestrogen receptor analysis of paraffin sections and cytosol samples of primary breast cancer in relation to outcome to adjuvant tamoxifen therapy. Acta Oncol 1996;35:17-22.

23 Soubeyran I, Quenel N, Coindre J-M, et al. PS2: a marker improving prediction of response to neoadjuvant tamoxifen in post-menopausal breast cancer patients. Br f Cancer 1996;74:1120-5.

24 Howanitz PJ. Quality assurance measurements in departments of pathology and laboratory medicine. Arch Pathol Lab Med 1990;114:1131-5.

24a Reiner A, Nuemeister B, Spona J, et al. Immunocytochemical localisation of oestrogen and progesterone receptors 1990;50:7057-61. 
25 McGuire WL, Chamness GC, Fuqua SA. Estrogen receptor variants in clinical breast cancer. Mol Endocrinol 1991;5: 1571-7.

26 Rhodes A, Jasani B, Balaton AJ, et al. Immunohistochemical demonstration of oestrogen and progesterone receptors: correlation of standards achieved on in house tumours with that assessment material in over 150 laboratories from 26 countries. F Clin Pathol
2000;53:292-301.

27 Larsson LI. Tissue preparation methods for light microscopic immunohistochemistry. Appl Immunohistochem 1993;1:2-16.
28 van Diest PJ, van Dam P, Henzen-Longmans SC, et al. A coring system for immunohistochemical staining: consensus report of the task force for basic

29 Williams JH, Mepham BL, Wright DH. Tissue preparation for immunocytochemistry. $\mathcal{F}$ Clin Pathol 1997;50:422-8.

30 Balaton AJ, Mathieu MC, Le Doussal V, on behalf of the Groupe d'Etude des Recepteurs Hormonaux par Immunohistochimie/FNCLCC. Optimization of heatinduced epitope retrieval for estrogen receptor determination by immunohistochemistry on paraffin sections: results of a multi-centric comparative study. Applied Immunohistochemistry 1996;4:259-63. 